\title{
PENGARUH KNOWLEDGE MANAGEMENT TERHADAP KINERJA KARYAWAN: STUDI KASUS DEPARTEMEN FRONT OFFICE SURABAYA PLAZA HOTEL
}

\author{
Natalia Kosasih \\ Dosen Program Manajemen Perhotelan, Fakultas Ekonomi, Universitas Kristen Petra \\ Email: natalia_bryan@yahoo.com \\ Sri Budiani \\ Alumnus Program Manajemen Perhotelan, Fakultas Ekonomi, Universitas Kristen Petra \\ Email: chen_swangswang@yahoo.com
}

\begin{abstract}
Abstrak: Pada era persaingan bebas saat ini diharapkan knowledge management dapat memberikan kontribusi yang baik bagi sumber daya manusia khususnya pada dunia hospitality. Penelitian ini bertujuan mengukur pengaruh dari knowledge management terhadap kinerja karyawan dengan studi kasus pada departemen front office di Surabaya Plaza Hotel. Hasil penelitian ini menunjukan bahwa knowledge management secara tidak langsung mempengaruhi kinerja karyawan, ada pengaruh yang signifikan antara personal knowledge terhadap job procedure, dan faktor yang paling dominan mempengaruhi kinerja karyawan adalah technology.
\end{abstract}

Kata kunci: knowledge management, kinerja karyawan, Surabaya Plaza Hotel.

\begin{abstract}
At the era of the global competition, knowledge management hopefully could provide sufficiently significant contributions to human resources, particularly among the hospitality world. This research is aimed at measuring the influence of knowledge management on the performance of the employees using case studies on the front office department at the Surabaya Plaza Hotel. The outcome of this research reveals that knowledge management indirectly affects the employee's performance, personal knowledge significantly affects job procedure, and the most dominant element of influencing the employee's performance is technology.
\end{abstract}

Keywords: knowledge management, working performance, Surabaya Plaza Hotel

Hotel sebagai salah satu industri jasa yang menyediakan jasa penginapan mengalami perkembangan yang sangat pesat, sehingga timbul banyak persaingan dalam industri ini. Di masa krisis yang melanda seperti saat ini, banyak pihak yang menyadari adanya tuntutan untuk memiliki kemampuan dalam membuat rencana pengembangan sumber daya manusia yang berkualitas.

Dalam upaya pengembangan ini, pihak manajemen khususnya di bidang jasa seperti hotel dapat melakukan perbaikan ke dalam, yaitu dengan melakukan performance appraisal. Menurut pendapat Rivai (2005) evaluasi kinerja (performance evaluation) yang dikenal juga dengan istilah penilaian kerja (performance appraisal), performance rating, performance assessment, employee evaluation, merit, rating, efficiency rating, service rating, pada dasarnya merupakan proses yang digunakan perusahaan untuk mengevaluasi job performance. Jika dikerjakan dengan benar, hal ini akan memberikan manfaat yang penting bagi karyawan, departemen sumber daya manusia, maupun bagi hotel itu sendiri.
Lebih lanjut kinerja karyawan akan mencapai hasil yang lebih maksimal apabila didukung dengan knowledge yang dimiliki. Setiap karyawan diharapkan dapat terus menggali pengetahuannya dan tidak hanya bergantung atau terpaku pada sistem yang ada. Sehingga dapat dikatakan bahwa setiap karyawan mempunyai peran di dalam meningkatkan perusahaannya. Seperti yang dikatakan oleh Fatwan (2006), faktor yang mempengaruhi lingkungan bisnis saat ini bukan lagi era informasi, tetapi sudah beralih ke era pengetahuan.

Menyadari adanya fenomena tersebut maka Surabaya Plaza Hotel melakukan suatu gebrakan dengan menerapkan knowledge management (KM) pada karyawannya. Berdasarkan penuturan Anshori (2004) selaku General Manager SPH, knowledge management yang diterapkan pada Surabaya Plaza Hotel terbagi menjadi 2 yaitu, tacit knowledge dan explicit knowledge. Yang pertama adalah pengetahuan individu yang didapat dari pengalaman keseharian, yang sulit diduplikasikan dan diajarkan kepada orang lain dimana penulis mengkategorikan dalam bentuk pengetahuan individu atau personal 
knowledge. Yang kedua, pengetahuan yang bisa ditransformasikan antar individu sehingga lebih mudah dideskripsikan ke dalam dokumen, praktik, pelatihan dan lain-lain dimana penulis mengkategorikan dalam bentuk job procedure, dan technology.

Pada akhirnya suatu sistem manajemen baru seperti knowledge management tentunya membutuhkan proses yang cukup lama untuk penyesuaiannya, sehingga dibutuhkan metode-metode yang kooperatif agar dapat membantu kelancaran sistem tersebut. Surabaya Plaza Hotel sendiri telah menjalankan sistem ini sejak pertengahan juni 2002 lalu, walaupun ada hambatan dan kesulitan yang dihadapi namun pasti ada hasil yang telah diraih oleh pihak manajemen sendiri.

\section{TEORI PENUNJANG}

\section{Konsep Knowledge Management}

Knowledge management menjadi guidance tentang pengelolaan intangible assets yang menjadi pilar perusahaan dalam menciptakan nilai (dari produk/jasa/solusi) yang ditawarkan perusahaan kepada pelanggannya. Oleh karena itu, pemahaman mengenai nilai buku perusahaan harus disertai dengan pemahaman nilai intangible assets perusahaan.

Jenis penerapan knowledge management ada dua, yaitu:

\section{Tacit Knowledge}

Pada dasarnya tacit knowledge bersifat personal, dikembangkan melalui pengalaman yang sulit untuk diformulasikan dan dikomunikasikan (Carrillo et al., 2004). Berdasarkan pengertiannya, maka tacit knowledge dikategorikan sebagai personal knowledge atau dengan kata lain pengetahuan yang diperoleh dari individu (perorangan).

Menurut Bahm (1995, p. 199) penelitian pada sifat dasar pengetahuan seketika mempertemukan perbedaan antara knower dan known, atau seringkali diartikan dalam istilah subject dan object, atau ingredient subjective dan objective dalam pengalaman.

Pengalaman yang diperoleh tiap karyawan tentunya berbeda-beda berdasarkan situasi dan kondisi yang tidak dapat diprediksi. Definisi experience yang diambil dari kamus bahasa Inggris adalah the process of gaining knowledge or skill over a period of time through seeing and doing things rather than through studying. Yang artinya proses memperoleh pengetahuan atau kemampuan selama periode tertentu dengan melihat dan melakukan hal-hal daripada dengan belajar.

\section{Explicit knowledge}

Explicit knowledge bersifat formal dan sistematis yang mudah untuk dikomunikasikan dan dibagi (Carrillo et al., 2004). Penerapan explicit knowledge ini lebih mudah karena pengetahuan yang diperoleh dalam bentuk tulisan atau pernyataan yang didokumentasikan, sehingga setiap karyawan dapat mempelajarinya secara independent. Explicit knowledge dalam penelitian ini adalah job procedure dan technology.

Job procedure adalah tanggung jawab atau tugas yang bersifat formal atau perintah resmi atau cara melakukan hal-hal. Berdasarkan pernyataan Anshori selaku pihak yang mencetuskan knowledge management, salah satu bentuk konkret dari explicit knowledge adalah Standard Operation Procedure. Standard Operation Procedure atau prosedur pelaksanaan dasar dibuat untuk mempertahankan kualitas dan hasil kerja, dimana tugas-tugas akan semakin mudah dikerjakan dan tamu akan terbiasa dengan sistem pelayanan yang ada.

Teknologi merupakan salah satu elemen pokok yang terdapat pada knowledge management, dikenal sebagai media yang mempermudah penyebaran explicit knowledge. Salah satu teknologi paling mutakhir yang saat ini digunakan oleh banyak perusahaan untuk proses penyebaran knowledge adalah intranet, dimana hal ini didasarkan pada kebutuhan untuk mengakses knowledge dan melakukan kolaborasi, komunikasi serta sharing knowledge secara "on line". Intranet atau disebut juga internal internet merupakan salah satu bentuk teknologi yang diterapkan di Surabaya Plaza Hotel. Intranet menawarkan kesempatan untuk menggunakan telekomunikasi yang maju yang telah dikembangkan dari internet.

\section{Konsep Kinerja Karyawan}

Kinerja merupakan hasil kerja atau karya yang dihasilkan oleh masing-masing karyawan untuk membantu badan usaha dalam mencapai dan mewujudkan tujuan badan usaha. Pada dasarnya kinerja dari seseorang merupakan hal yang bersifat individu karena masing-masing dari karyawan memiliki tingkat kemampuan yang berbeda. Kinerja seseorang tergantung pada kombinasi dari kemampuan, usaha, dan kesempatan yang diperoleh (Dale, 1992, p. 3).

Menurut Bernardin dan Russel (1993, p. 382) terdapat 6 kriteria untuk menilai kinerja karyawan, yaitu:

1. Quality

Tingkatan dimana proses atau penyesuaian pada cara yang ideal di dalam melakukan aktifitas atau memenuhi aktifitas yang sesuai harapan. 
2. Quantity

Jumlah yang dihasilkan diwujudkan melalui nilai mata uang, jumlah unit, atau jumlah dari siklus aktifitas yang telah diselesaikan.

3. Timeliness

Tingkatan di mana aktifitas telah diselesaikan dengan waktu yang lebih cepat dari yang ditentukan dan memaksimalkan waktu yang ada untuk aktifitas lain.

4. Cost effectiveness

Tingkatan dimana penggunaan sumber daya perusahaan berupa manusia, keuangan, dan teknologi dimaksimalkan untuk mendapatkan hasil yang tertinggi atau pengurangan kerugian dari tiap unit.

5. Need for supervision

Tingkatan dimana seorang karyawan dapat melakukan pekerjaannya tanpa perlu meminta pertolongan atau bimbingan dari atasannya.

6. Interpersonal impact

Tingkatan di mana seorang karyawan merasa percaya diri, punya keinginan yang baik, dan bekerja sama di antara rekan kerja.

Namun dari ke-6 kriteria tersebut, terdapat kriteria yang penulis anggap tidak relevan untuk penelitian ini, yaitu cost effectiveness dikarenakan yang dapat mengetahui dan melakukan pengukuran keefektifan biaya adalah karyawan pada level managemen bukan karyawan operasional, dimana dalam penelitian ini yang dipilih sebagai anggota sampel adalah karyawan operasional.

\section{Hubungan Antara Knowledge Management dan Kinerja Karyawan}

Untuk menghasilkan kinerja yang baik, maka perusahaan membutuhkan sistem yang baik pula. Sistem ini bukan hanya peraturan atau standar yang ada melainkan juga melibatkan pihak-pihak yang terkait langsung yaitu sumber daya manusianya. Salah satu sistem manajemen yang menawarkan suatu disiplin yang memperlakukan intelektual sebagai aset yang dikelola adalah knowledge management (Honeycutt, 2002), yang diukur dengan 3 variabel yaitu personal knowledge, job procedure, dan technology. Dalam prakteknya knowledge management dapat menjadi guidance tentang pengelolaan intangible asset yang menjadi pilar perusahaan dalam menciptakan nilai. Perusahaan perlu mengetahui sejauh mana knowledge management berperan di dalam meningkatkan kinerja karyawan khususnya di indusrti perhotelan. Maka dari itu, kinerja karyawan akan diukur melalui 5 kriteria penilaian karyawan, yaitu: quality, quantity, timeliness, need for supervision, dan interpersonal impact.

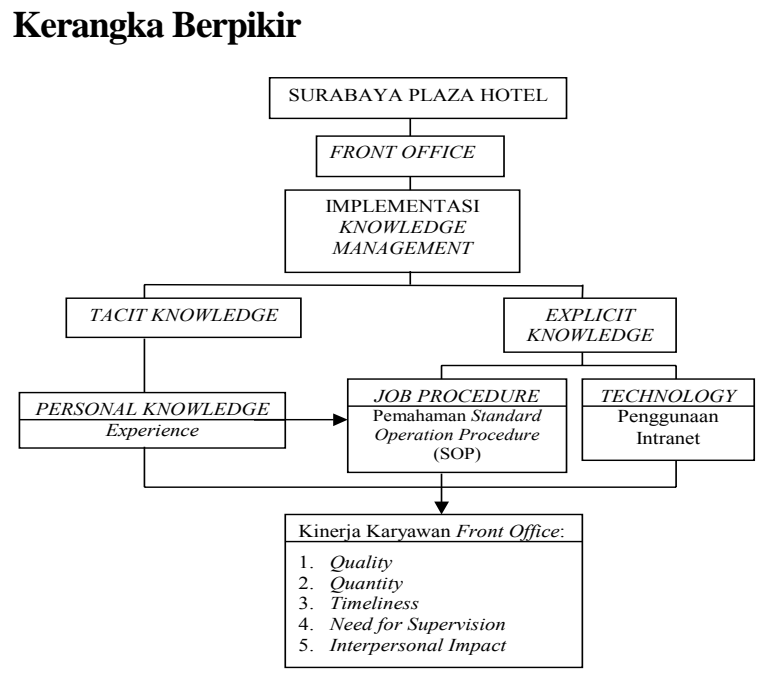

\section{Gambar 1. Kerangka Berpikir}

\section{Hipotesis}

Berdasarkan teori di atas penulis menyusun hipotesis sebagai berikut:

1. Personal knowledge, job procedure, technology secara signifikan mempengaruhi kinerja karyawan hotel.

2. Personal knowledge berpengaruh terhadap pemahaman karyawan akan job procedure.

3. Yang paling dominan mempengaruhi kinerja karyawan hotel adalah job procedure.

\section{METODE PENELITIAN}

\section{Jenis Penelitian, Populasi dan Sampel}

Jenis penelitian yang digunakan pada penelitian ini adalah penelitian penjelasan (explanatory research) dengan metode kuantitatif. Populasi penelitian ini adalah karyawan departemen front office di Surabaya Plaza Hotel yang berjumlah 43 orang.

Metode pengambilan sampel yang digunakan adalah judgement sampling yaitu sampel yang dipilih berdasarkan karakteristik tertentu, dalam hal ini adalah karyawan front office Surabaya Plaza Hotel pada level operasional yang bekerja minimal 1 tahun sebanyak 26 orang.

\section{Jenis dan Sumber Data}

Dalam penelitian ini jenis data yang dikumpulkan, yaitu:

1. Data primer merupakan data yang diperoleh peneliti untuk tujuan khusus dalam menjawab masalah penelitian (Malhotra, 2004). Data primer dalam penelitian ini adalah data mengenai implementasi knowledge management yang terdiri dari: personal knowledge, job procedure, 
technology. Selain itu yang termasuk data primer adalah data tentang kinerja karyawan berdasarkan performance appraisal form yang bersumber dari data sekunder Surabaya Plaza Hotel.

2. Data sekunder adalah data yang dikumpulkan untuk tujuan tertentu selain dari masalah penelitian (Malhotra, 2004). Data penelitian sekunder adalah berupa data mengenai Standard Operation Procedure karyawan front office, struktur organisasi Surabaya Plaza Hotel dan struktur organisasi departemen front office, serta job description subdivisi front office antara lain reservation, reception, business centre, telephone operator, dan concierge.

\section{Definisi Operasional Variabel}

1. Personal knowledge adalah pengetahuan yang diperoleh karyawan front office berupa pengalaman baik dari kejadian sehari-hari ataupun dari sumber lainnya. Indikator empirik:

a. Setiap karyawan harus memiliki pengalaman kerja minimal 1 tahun di bidangnya.

b. Karyawan yang berpengalaman cenderung bekerja lebih profesional daripada karyawan yang belum memiliki pengalaman sama sekali.

c. Pengalaman bukan hanya diperoleh dari diri sendiri tetapi juga dari orang lain.

d. Mendapatkan pengalaman baru setiap hari.

e. Pengalaman yang diperoleh memperkaya pengetahuan.

f. Akan lebih baik apabila mempelajari pengalaman dari departemen lain, walaupun tidak termasuk dalam tanggung jawab karyawan satu departemen.

g. Mengkomunikasikan pengalaman kerja dengan rekan kerja.

h. Ikut ambil bagian dalam forum 'Sharing bestpractices' dan membagikan pengalaman untuk kemajuan perusahaan.

i. Kegiatan'Sharing best-practices' bermanfaat untuk menambah pengalaman.

j. Masalah yang dihadapi dapat dijadikan pelajaran yang berharga

2. Job procedure adalah tanggung jawab atau tugas yang harus dijalankan oleh karyawan front office berdasarkan Standard Operation Procedure yang ada dan sifatnya formal. Indikator empirik:

a. SOP dapat menjamin terciptanya produk yang standar meskipun dikerjakan oleh orang yang berbeda.

b. Dengan adanya SOP pekerjaan menjadi terarah dan terkoordinir.

c. SOP merupakan sarana komunikasi dalam mencapai sasaran dan tujuan perusahaan.

d. SOP dapat menunjukkan tanggung jawab kerja dengan sangat jelas. e. SOP dapat meningkatkan produktivitas kerja dan mengefesiensi waktu.

f. Pemahaman mengenai SOP sudah sangat baik.

g. SOP dapat dijadikan acuan dalam pelaksanaan pelatihan dalam departemen saya.

h. SOP dalam departemen telah memenuhi standar yang ada.

i. Seorang karyawan yang memiliki ide dari pengalaman yang dimilikinya dan diubah dalam bentuk SOP merupakan gagasan yang baik.

j. SOP yang ada sudah memberikan hasil yang cukup efektif.

3. Technology adalah media penyebaran informasi melalui sarana intranet yang digunakan untuk mendukung tiap kegiatan kerja di dalam perusahaan. Indikator empirik:

a. Pemahaman tentang intranet sudah baik.

b. Frekuensi menggunakan fasilitas intranet selama jam kerja.

c. Intranet merupakan sarana yang sesuai untuk mendapat dan menyebarkan informasi.

d. Pengetahuan akan intranet wajib diketahui oleh semua karyawan baik staff maupun karyawan penyelia.

e. Fasilitas intranet yang ada saat ini sangat membantu proses kerja karyawan.

f. Fasilitas intranet dapat meningkatkan efisiensi kerja baik dari segi waktu dan biaya.

g. Frekuensi penggunaan intranet untuk mencari informasi dan menambah pengetahuan.

h. Pemanfaatan teknologi di departemen sudah benar-benar efektif.

i. Fasilitas Intranet sangat membantu di dalam menyimpan dan mengirim data.

\section{TEKNIK ANALISIS DATA}

\section{Statistik Deskriptif}

Dalam penelitian ini penulis melakukan perhitungan distribusi frekuensi dan mean (nilai rata-rata) untuk memberikan gambaran atau deskripsi dari data yang diperoleh.

2. Analisis Path Dengan Menggunakan Permodelan SEM (Structural Equation Modeling) Menurut Basuki (2006) prinsip structural equation model merupakan pendekatan terintegrasi dari confirmatory factor analysis dan path analysis (analisis jalur). Analisis jalur mempelajari apakah hubungan yang terjadi disebabkan oleh pengaruh langsung dan tidak langsung dari variabel independen terhadap variabel dependen, mempelajari ketergantungan sejumlah variabel dalam suatu model (model kausal), menganalisis hubungan antar variabel dari model kausal yang telah dirumuskan oleh peneliti atas dasar 
pertimbangan teoritis, serta menguji seperangkat hipotesis kausal dan menginterpretasikan hubungan tersebut (langsung atau tidak langsung).

\section{Partial Least Square (PLS)}

Partial least square dikembangkan sebagai alternatif untuk situasi dimana dasar teori pada perancangan model lemah dan atau indikator yang tersedia tidak memenuhi model pengukuran refleksif. Partial least square merupakan metode analisis yang powerful karena dapat diterapkan pada semua skala data, tidak membutuhkan banyak asumsi dan ukuran sample tidak harus besar.

\section{ANALISIS DAN PEMBAHASAN}

\section{Analisis Profil Responden}

Hasil analisis data profil responden yang diperoleh penulis yaitu responden laki-laki sebanyak 20 orang $(76,9 \%)$, responden perempuan sebanyak 6 orang $(23,1 \%)$, rata-rata usia responden 32 tahun. Prosentase latar belakang pendidikan paling banyak adalah lulusan SMU sebanyak 10 orang $(38,5 \%)$. Responden dalam penelitian ini paling banyak berasal dari sub-divisi concierge sebanyak 14 orang $(53,8 \%)$. Rata-rata responden menekuni bidangnya saat ini adalah 8 tahun.

\section{Analisis Partial Least Square}

\section{Diagram Jalur}

Pada bagian ini penulis membuat diagram jalur yang akan membahas mengenai analisis pengaruh personal knowledge, job procedure, dan technology terhadap kinerja karyawan hotel. Selain itu, analisis ini juga digunakan untuk mengetahui variabel mana yang paling dominan berpengaruh terhadap kinerja karyawan. Dalam pengolahan data kuesioner penulis menggunakan program SPSS. Berikut diagram jalur untuk partial least square:

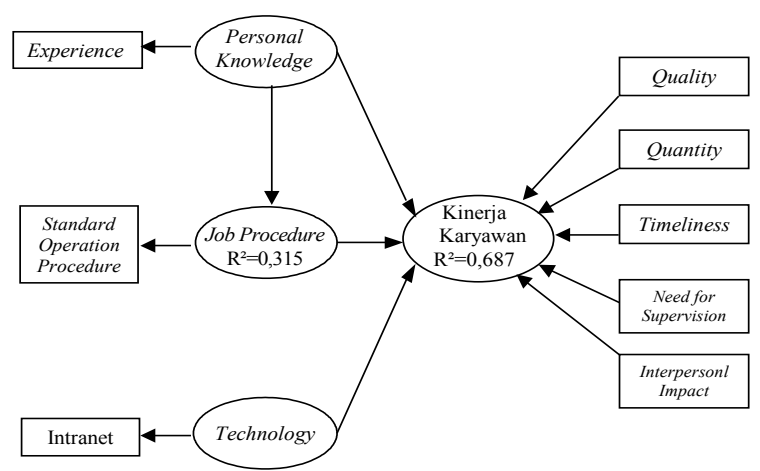

Gambar 2. Diagram Jalur Partial Least Square Pengaruh Knowledge Management Terhadap Kinerja Karyawan
Analisis statistik yang digunakan adalah Partial Least Square (PLS) yang persamaannya adalah:

a. Job procedure $=\alpha$ personal knowledge

b. Kinerja $=\beta 1$. personal knowledge $+\beta 2$. job procedure $+\beta 3$. technology

\section{$\underline{\text { Goodness of Fit }}$}

Dalam Partial Least Square (PLS) terdapat 2 macam model yaitu:

a. Outer Model

Composite Reliability

Kelompok indikator yang mengukur sebuah variabel memiliki reliabilitas komposit yang baik jika memiliki composite reliability $\geq 0,7$, walaupun bukan merupakan standar yang absolut. Dalam hal ini penulis tidak melakukan uji reliabilitas terhadap variabel kinerja dikarenakan data tersebut merupakan data sekunder dari Surabaya Plaza Hotel. Berikut penulis menyajikan tabel composite reliability.

\section{Tabel 1. Composite Reliability}

\begin{tabular}{lcc}
\hline Variabel Laten & $\begin{array}{c}\text { Koefisien } \\
\text { Reliability }\end{array}$ & $\begin{array}{c}\text { Jumlah } \\
\text { Indikator }\end{array}$ \\
Personal & 0,788 & 10 \\
Knowledge & 0,806 & 10 \\
Job procedure & 0,605 & 9 \\
Technology & \\
\hline
\end{tabular}

Sumber: Data primer, diolah

Dari Tabel 1 dapat dilihat bahwa variabel personal knowledge dan job procedure dianggap reliabel dikarenakan composite reliabilitynya $\geq 0,7$. Sedangkan variabel technology dianggap tidak reliabel dikarenakan composite reliability-nya $\leq 0,7$.

b. Inner Model

Goodness of fit model diukur menggunakan Rsquare variabel laten dependen dengan interpretasi yang sama dengan regresi $Q$-square predictive relevance untuk model struktural, mengukur seberapa baik nilai observasi dihasilkan oleh model dan juga estimasi parameternya. Nilai Q-square harus $>0$ di mana menunjukkan model memiliki predictive relevance. Berikut model regresi dalam penelitian ini:

1. Personal knowledge $=\alpha$ job procedure $\left(\mathrm{R}^{2}=0,315\right)$ Yang artinya kemampuan personal knowledge untuk menjelaskan keragaman pemahaman tentang job procedure adalah sebesar 0,315 atau 31, $5 \%$.

2. Kinerja $=\beta 1$. personal knowledge $+\beta 2$. job procedure $+\beta 3$. technology $\left(\mathrm{R}^{2}=0,687\right)$

Yang artinya kemampuan kinerja untuk menjelaskan keragaman personal knowledge, job 
procedure, dan technology adalah sebesar 0,687 atau $68,7 \%$.

Selanjutnya perolehan $\mathrm{R}^{2}$ dimasukkan ke dalam persamaan $Q$-square berikut:

$$
\begin{aligned}
\mathrm{Q}^{2} & =1-(1-\text { job procedure })(1-\text { kinerja }) \\
& =1-(1-0,315)(1-0,687) \\
& =1-(0.685)(0,313) \\
& =0,785595
\end{aligned}
$$

Dari perhitungan ini nilai $\mathrm{Q}^{2}=0,785595>0$, yang berarti model memiliki predictive relevance, di mana semakin mendekati 1 berarti model semakin baik.

3. Analisis Uji Hipotesis

Pada pengujian ini penulis akan melakukan resampling bootstraping untuk mengetahui apakah nilai antara personal knowledge, job procedure, technology akan bersifat signifikan mempengaruhi kinerja karyawan dan apakah nilai dari variabel personal knowledge bersifat

\begin{tabular}{|c|c|c|c|c|c|}
\hline & $\begin{array}{c}\text { original } \\
\text { sample } \\
\text { estimate }\end{array}$ & $\begin{array}{c}\text { mean of } \\
\text { sub- } \\
\text { samples }\end{array}$ & $\begin{array}{l}\text { Standard } \\
\text { deviation }\end{array}$ & $\begin{array}{c}\text { T- } \\
\text { Statistic }\end{array}$ & P_Value \\
\hline $\begin{array}{l}\text { personal - } \\
\text { >jobpros }\end{array}$ & 0.561 & 0.566 & 0.331 & 1.695 & 0.045349 \\
\hline $\begin{array}{l}\text { personal - } \\
\text { > kinerja }\end{array}$ & 0.499 & 0.235 & 0.32 & 1.557 & 0.060052 \\
\hline $\begin{array}{l}\text { jobpros - } \\
\text { >kinerja }\end{array}$ & 0.099 & 0.11 & 0.286 & 0.345 & 0.36512 \\
\hline $\begin{array}{l}\text { Tekno - } \\
\text { >kinerja }\end{array}$ & 0.562 & 0.382 & 0.344 & 1.632 & 0.051655 \\
\hline
\end{tabular}
signifikan mempengaruhi job procedure. Statistik uji yang digunakan adalah statistik $t$ atau uji t.

Tabel 2. Analisis Uji t

Sumber: Data primer, diolah.

a. Hipotesis statistik

$\mathrm{H} 1=$ terdapat pengaruh positif antara personal knowledge, job procedure, technology terhadap kinerja karyawan.

$\mathrm{H} 2=$ terdapat pengaruh positif antara personal knowledge terhadap job procedure.

$\mathrm{H} 3=$ job procedure merupakan intervening an-

b. Keputusan tara personal knowledge dengan kinerja.

1. Pengambilan keputusan berdasarkan $p$-value Hipotesis inner model 1 :

$\mathrm{P} 1=0.060052<\alpha=0,10$, sehingga signifikan (personal knowledge)

$\mathrm{P} 2=0.345>\alpha=0,10$, sehingga tidak signifikan (job procedure)

$\mathrm{P} 3=0.051655<\alpha=0,10$, sehingga signifikan (technology)

Dari data di atas dapat disimpulkan bahwa Ho diterima, karena tidak semua variabel bebas berpengaruh secara signifikan terhadap kinerja karyawan hotel. Hanya variabel personal knowledge, dan technology yang berpengaruh secara signifikan, sedangkan job procedure tidak berpengaruh secara signifikan terhadap kinerja karyawan hotel. Dengan demikian maka hipotesis yang menyatakan bahwa ada pengaruh yang signifikan antara personal knowledge, job procedure, technology terhadap kinerja karyawan hotel ditolak.

Hipotesis inner model 2:

$\mathrm{P} 4=0.045349<\alpha=0,10$, sehingga signifikan (personal knowledge terhadap job procedure)

Dari data di atas dapat disimpulkan bahwa Ho ditolak, karena personal knowledge berpengaruh secara signifikan terhadap job procedure. Dengan demikian hipotesis yang menyatakan bahwa ada pengaruh antara personal knowledge terhadap pemahaman karyawan akan job procedure diterima.

2. Pengambilan keputusan berdasarkan perbandingan $t$ hitung dengan $t$ tabel

thitung $1=1.557$

thitung $2=0.345$

thitung $3=1.632$

Karena $\mathrm{t}$ hitung $1=1.557>\mathrm{t}$ tabel $=1.282, \mathrm{t}$ hitung $2=0.345<\mathrm{t}$ tabel $=1.282$, $\mathrm{t}$ hitung $3=1.632>t$ tabel $=1.282$, apabila melihat besarnya pengaruh dari tiap variabel maka variabel yang berpengaruh paling dominan adalah variabel technology. Dengan demikian hipotesis yang menyatakan bahwa pengaruh yang paling dominan adalah job procedure ditolak.

\section{Pembahasan Hasil Penelitian}

1. Dari keseluruhan analisis yang telah dilakukan penulis menemukan bahwa pengaruh langsung antara job procedure ke kinerja menunjukkan arah yang positif namun nilainya sangat kecil yaitu sebesar 0,099 (perolehan angka dapat dilihat pada tabel 4.26). Namun apabila melihat pengaruh secara total antara personal knowledge dan job procedure ke kinerja maka perolehan nilainya akan lebih tinggi, dengan perhitungan sebagai berikut:

Pengaruh total terhadap kinerja $=(0,561 \times 0,099)$ $+0,499=\underline{0,555}$

Yang artinya job procedure yang diimbangi dengan personal knowledge akan memberikan pengaruh yang baik bagi kinerja karyawan hotel.

2. Penulis juga menemukan bahwa pemahaman Standard Operation Procedure sebagai indikator 
dari job procedure dalam jangka waktu yang panjang (long run) tidak menunjukkan pengaruh yang kuat terhadap kinerja, hal ini juga dapat dilihat dari jumlah responden atau karyawan hotel yang lama menekuni bidangnya saat ini kebanyakan lebih dari 9 tahun. Dengan jangka waktu yang lama tersebut maka karyawan tidak lagi terpaku pada Standard Operation Procedure yang ada, namun pada prosesnya karyawan juga belajar dari pengalaman yang diperoleh.

3. Hasil temuan yang penulis peroleh dari hasil penelitian sebelumnya tentang knowledge management yang dipaparkan oleh beberapa peneliti seperti Malhotra dan Ardichvili (2002) dimana dalam penelitiannya di bidang teknologi atau $e$ business, dipaparkan mengenai pentingnya peranan knowledge management yang disertai dengan kemampuan individu atau karyawan dalam perusahaan. Selama ini banyak perusahaan melakukan investasi pada aspek teknologinya agar selalu up to date, tetapi tidak memperhatikan sumber daya manusia yang dimiliki, akibatnya kinerja perusahaan tidak maksimal dikarenakan tidak diimbangi dengan pembekalan pengetahuan terhadap sumber daya manusianya. Contoh kasus pada perusahaan Xerox, John Seely Brown selaku direktur perusahaan tersebut melakukan investasi lebih dari USD 1 milyar pada teknologi dalam perusahaannya. Namun peningkatan efisiensi dan efektifitas pada pengetahuan karyawan sangat minim akhirnya kinerja perusahaan menjadi tidak maksimal. Sedangkan pada penelitian lain yang dilakukan Donoghaue, Harris dan Weitzman mengemukakan bahwa knowledge management yang efektif membutuhkan kombinasi dari berbagai macam elemen organisasi contohnya teknologi dengan praktisi sumber daya manusia, struktur organisasi dan budaya dalam artian untuk memastikan bahwa pengetahuan yang benar diperlukan untuk bertahan pada saat yang tepat. Penulis juga menemukan selama ini kebanyakan penelitian knowledge management dilakukan pada industri di bidang teknologi, hal ini dikarenakan industri teknologi mempunyai perkembangan produk yang sangat cepat regenerasinya sehingga membutuhkan orang-orang yang selalu memiliki inovasi-inovasi mutakhir agar dapat terus exist dalam dunia bisnis. Pada intinya perusahaan dalam bidang teknologi sangat mementingkan kemampuan individu dalam menggali pengetahuan yang dimilikinya untuk mengembangkan perusahaan. Dan kesimpulan yang diperoleh bahwa penerapan knowledge management harus diikuti antara pengetahuan yang dimiliki oleh intangible asset yaitu setiap individu atau karyawan dalam suatu perusahaan dan tangible asset seperti teknologi yang dimiliki perusahaan tersebut. Saat ini penelitian dalam bidang jasa mengenai penerapan knowledge management masih sangat jarang ditemukan, maka dari itu penulis mengangkat penelitian ini sebagai gambaran baru bagi dunia jasa bahwa penerapan knowledge management juga dapat memberikan manfaat nyata bagi kinerja perusahaan khususnya di industri perhotelan.

\section{KESIMPULAN DAN SARAN}

\section{Kesimpulan}

1. Responden paling banyak berusia 25 tahun, dengan rata-rata lama menekuni bidangnya saat ini lebih dari 9 tahun.

2. Pada pengaruh langsung personal knowledge, job procedure dan technology tidak berpengaruh secara signifikan terhadap kinerja karyawan. Namun pada pengaruh tidak langsung personal knowlegde dan job procedure berpengaruh secara signifikan terhadap kinerja karyawan. Hal ini berarti dengan pengalaman yang dimiliki dan pemahaman Standard Operation Procedure yang baik akan berpengaruh pada kinerja karyawan.

3. Terdapat pengaruh antara personal knowledge ke job procedure, dimana hal ini berarti dengan personal knowledge yang baik maka pemahaman akan job procedure juga baik.

4. Faktor yang paling dominan mempengaruhi kinerja adalah technology. Hal ini dikarenakan pada departemen front office banyak menggunakan fasilitas technology untuk mendukung proses kerja, contohnya pada sub-divisi reception yang banyak menggunakan intranet dan fidelio untuk menyimpan data dan memberikan informasi antar departemen.

5. Menurut penulis secara keseluruhan implementasi knowledge management di Surabaya Plaza Hotel sudah cukup baik, hal ini juga dapat dilihat dari program-program yang ada yang menawarkan bentuk pelatihan atau training agar karyawan diberi kesempatan untuk mengembangkan pengetahuan yang dimilikinya. Program lain yang diadakan yaitu sharing best-practices yang menjadi wadah bagi para karyawan untuk melakukan transfer knowledge demi peningkatan kinerja hotel. 


\section{Saran}

Dari penjelasan pada bab-bab sebelumnya, penulis menyarankan beberapa hal yang diharapkan dapat membantu pihak hotel agar dapat meningkatkan kualitas kinerja karyawannya, yaitu:

1. Pengetahuan akan job procedure hendaknya disertai dengan personal knowledge yang baik dari setiap karyawan.

2. Pihak hotel diharapkan untuk terus menggali potensi sumber daya manusianya, dengan aktif mengadakan kegiatan dan training yang bermanfaat.

3. Pihak hotel diharapkan dapat melakukan program pemberian award bagi karyawan yang aktif dan berprestasi atau yang memiliki wawasan luas tidak hanya dalam departemennya saja melainkan juga pada departemen lain, sehingga karyawan mendapatkan motivasi agar tidak malas dalam mengembangkan pengetahuan. Sehingga pada akhirnya dapat memberikan manfaat bagi perusahaan dan bagi karyawan itu sendiri.

4. Pihak hotel diharapkan terus mengembangkan penerapan knowledge management dan menyeimbangkan antara intangible asset yang dimiliki dengan tangible asset atau aspek fisik yang mendukung.

Lebih lanjut, penelitian ini memiliki beberapa keterbatasan, yaitu:

1. Jumlah sampel yang kecil dan hanya terbatas pada salah satu departemen dalam hotel yaitu front office, sehingga tidak memungkinkan untuk melakukan generalisasi.

2. Data tentang penilaian kinerja merupakan data sekunder, dimana dari hal ini penulis tidak mengetahui metodologi pengukuran kinerja yang dilakukan oleh Surabaya Plaza Hotel sehingga tingkat akurasinya tidak diketahui dengan pasti.

3. Tidak semua variabel dari tacit dan explicit diukur dalam penelitian ini penulis hanya membatasi pada tiga variabel saja yaitu personal knowledge, job procedure, dan technology.

Berpijak dari keterbatasan tersebut, penulis memberikan saran untuk penelitian selanjutnya, yaitu:

1. Diharapkan untuk melakukan penelitian knowledge management dengan memperluas karakteristik sampel pada beberapa kategori hotel sebagai langkah generalisasi.

2. Penelitian juga dapat dilakukan dengan menghubungkan knowledge management dengan kepuasan pelanggan.
3. Memperbesar jumlah sampel dengan tujuan agar penelitian tentang knowledge management memberikan hasil yang lebih akurat.

\section{DAFTAR REFERENSI}

Ardichvilli, A. (2002). Knowledge management, human resource department, and internet technology. Advances In Developing Human Resources, 4, (451), pp. 4-5.

Anshori, Y. (2004). Analisis keunggulan bersaing melalui penerapan knowledge management dan knowledge-based strategy di Surabaya Plaza Hotel. Jurnal Manajemen Perhotelan, $1,(2)$, pp. $39-53$.

Bateman, T. S., \& Snell, S. A. (2002). Management competing in the new era ( $5^{\text {th }}$ ed.). Irwin: McGraw-Hill.

Basuki, H. (2006, September). Modul workshop metodologi penelitian SEM. Surabaya: ITS.

Bernardin, R. A. (1993). Human resource management: An experimental approach. Singapore: McGraw Hill.

Carrillo, P., Robinson, H., Al-Ghassani, A., Anumba, C. (2004). Knowledge management in UK construction: Strategies, resources and barriers. Project Management Journal, 35, (1), p. 46.

Dajan, A. (1996). Pengantar metode statistik (jilid 2). Jakarta: LPES.

Djohar, S. (2000, Juli). Knowledge management. Majalah manajemen, pp. 28-30.

Fatwan, S., (2006, Februari). Knowledge management, warna cerah dunia bisnis Indonesia. $S W A$, 4, (22), p. 53.

Ferdinand, A. (2002). Structural equation modeling dalam penelitian manajemen aplikasi modelmodel rumit dalam penelitian untuk tesis magister \& disertasi doktor. Semarang: Fakultas Ekonomi Undip.

Honeycutt, J. (2005). Knowledge management strategies; Strategi manajemen pengetahuan. Jakarta: PT. Elex Media Komputindo.

Kuncoro, M. (2004). Metode kuantitatif: Teori dan aplikasi untuk bisnis dan ekonomi $\left(2^{\text {nd }}\right.$ ed.). Yogyakarta: UPP AMP YKPN. 
Malhotra, N.K. (1996). Marketing research. Prentice Hall International, inc. London.

(2004). Marketing research: An applied orientation ( $4^{\text {th }}$ ed.). Prentice Hall: New Jersey.

Malhotra, Y. (2000). Knowledge management for [e] business performance information strategy. The Executive Journal, 16, (4), pp. 5-16.

(2003, September). Is knowledge the ultimate competitive advantage? Business Management Asia, pp. 66-69.

Nykiel. (2005). Hospitality management strategies. USA: Pearson Prentice Hall.

O'Shannessy., \& Minett. (2003). Introduction to hospitality: The road to hospitality ( $2^{\text {nd }}$ ed.). Australia: Pearson Education.

Rivai, B.M. (2005). Performance appraisal. Jakarta: PT RajaGrafindo Persada.
Robbins \& Coulter. (2002). Management $\left(7^{\text {th }}\right.$ ed.).USA: Prentice Hall.

Santoso, S. (2000). Buku latihan SPSS: Statistik parametrik. Jakarta: Elex Media Komputindo.

Simamora, B. (1997). Panduan riset perilaku konsumen. Jakarta: Gramedia Pustaka Utama.

Singarimbun, E. (1991). Metode penelitian survai. Jakarta: LP3ES.

Soelaeman, T. S. (2004, November). Mengintip penerapan KM di Surabaya Plaza Hotel. Majalah SWA, 24, (20), pp. 72 - 74.

Solimun. (2007). Memahami metode analisis kuantitatif mutakhir. Lokakarya statistik mutakhir di Universitas Kristen Petra, Surabaya.

Sugiarto, E. (1997). Operasional kantor depan hotel. Jakarta: Gramedia Pustaka Utama.

Sulastiyono, A. (2001). Manajemen penyelenggara hotel. Bandung: Alfabeta. 